OPEN ACCESS

Edited by:

Nathan Wales,

University of York, United Kingdom

Reviewed by:

Alexander Herbig,

Max Planck Institute for the Science of Human History (MPI-SHH),

Germany

Andrew Thomas Ozga

Nova Southeastern University,

United States

*Correspondence:

Luis A. Arriola

luis.arriola@adelaide.edu.au

Laura S. Weyrich

Isw132@psu.edu

Specialty section:

This article was submitted to

Paleoecology,

a section of the journal

Frontiers in Ecology and Evolution

Received: 18 October 2019

Accepted: 10 February 2020

Published: 16 June 2020

Citation:

Arriola LA, Cooper A and

Weyrich LS (2020)

Palaeomicrobiology: Application of Ancient DNA Sequencing to Better

Understand Bacterial Genome

Evolution and Adaptation.

Front. Ecol. Evol. 8:40.

doi: 10.3389/fevo.2020.00040

\section{Palaeomicrobiology: Application of Ancient DNA Sequencing to Better Understand Bacterial Genome Evolution and Adaptation}

\author{
Luis A. Arriola ${ }^{1 *}$, Alan Cooper ${ }^{1,2}$ and Laura S. Weyrich ${ }^{1,3,4 *}$ \\ ${ }^{1}$ Australian Centre for Ancient DNA, School of Biomedical Sciences, University of Adelaide, Adelaide, SA, Australia, ${ }^{2}$ South \\ Australian Museum, Adelaide, SA, Australia, ${ }^{3}$ Centre for Australian Biodiversity and Heritage, School of Biological Sciences, \\ University of Adelaide, Adelaide, SA, Australia, ${ }^{4}$ Department of Anthropology and The Huck Institutes of Life Sciences, \\ The Pennsylvania State University, University Park, PA, United States
}

Next generation sequencing (NGS) has unlocked access to the wide range of noncultivable microorganisms, including those present in the ancient past. The study of microorganisms from ancient sources (palaeomicrobiology) using DNA sequencing now provides a unique opportunity to examine ancient microbial genomic content, explore pathogenicity, and understand microbial evolution in greater detail than ever before. As a result, current studies have focused on reconstructing the evolutionary history of a number of human pathogens involved in ancient and historic pandemic events. These studies have opened the door for a variety of future palaeomicrobiology studies, which can focus on commensal microorganisms, species from non-human hosts, information from host-genomics, and the use of bacteria as proxies for additional information about past human health, behavior, migration, and culture. Here, we describe the origin and the historical and recent advances in the field of palaeomicrobiology, review some of the most notable ancient pathogenic microorganism studies, and provide perspectives on how NGS and whole genome information from ancient microorganisms contributes to our understanding of bacterial evolution on a broader scale. We conclude by exploring the application of newly developed tools in palaeomicrobiology and discussing how future studies can improve our current understanding of non-pathogenic microbes.

Keywords: ancient DNA, pathogens, microbiome, microbiota, genomics, commensals, palaeomicrobiology, palaeomicrobiomics

\section{INTRODUCTION}

The advancement of DNA sequencing technologies has expanded significantly our understanding of the biology and evolution of microorganisms and drastically added to the body of literature using classical microbiological methodologies (culture-based assays, in vitro studies, microscopy, etc.). Today, more than 130,000 complete or near-complete bacterial genomes from $>50$ different phyla have been sequenced along with a variety of microorganisms, including archaea, fungi, and viruses (Genomes Online Database, GOLD v.7; Reddy et al., 2014; Land et al., 2015). Extensive genomic data from these microorganisms provided new insights into genome content, adaptation, and 
evolution, and opened up the opportunity to explore relationships between different related strains and across organisms from different kingdoms (Bryant et al., 2012; Bentley and Parkhill, 2015). However, we still know very little about microbial genome evolution over long time scales, i.e., over the course of anatomically modern human evolution, or the phenotypic, functional consequences of those long-term adaptations that do not result in disease.

Historically, microbial genomic sequencing was limited by the ability to culture pure strains; however, next-generation sequencing technologies have allowed researchers to rapidly access genomic information from uncultivable organisms (Riesenfeld et al., 2004; Schloss and Handelsman, 2005). Due to molecular decay and DNA fragmentation, microorganisms in ancient samples (i.e., hundreds to thousands of years old) are prime examples of taxa that cannot be cultivated. As a consequence, the use of ancient DNA (aDNA) sequencing in palaeomicrobiology - the study of ancient microorganisms emerged with a focus on diagnosing and characterizing the pathogenic agents from past human pandemics using novel molecular techniques, such as hybridization enrichment and shotgun sequencing (Drancourt and Raoult, 2005). The use of genetics in paleomicrobiology now almost completely obscures historical methods, such as microscopy, to detect or characterize ancient microbes. The ability to interrogate a mixture of genetic material from all of the microorganisms present in a sample (the microbiome) using metagenomic approaches has also resulted in renewed interest and significant technical and analytical advances in the palaeomicrobiology field (Adler et al., 2013; Warinner et al., 2014; Harkins and Stone, 2015). By comparing ancient and modern microorganisms, researchers have now reconstructed the evolutionary history of several pathogens over extensive timescales and traced specific genomic changes that are linked to past diseases and epidemics (Anastasiou and Mitchell, 2013; Harkins and Stone, 2015; Bos et al., 2019).

In the following review, we examine how the field of palaeomicrobiology has been enhanced through the application of aDNA analysis and the use of next-generation sequencing technologies. We discuss the findings from several key ancient human bacterial pathogens, as well as several viral and eukaryotic pathogens, to explore how these techniques might be used on other microbes. We summarize how existing studies have revolutionized our understanding of microbial evolution and explore the existing pitfalls and barriers within this new research field. We conclude by describing how aDNA research can be improved in the future to address existing epidemiological and evolutionary questions, especially in non-pathogenic microbes.

\section{ORIGIN AND DEVELOPMENT OF ANCIENT MICROBIAL STUDIES USING ANCIENT DNA}

Ancient DNA is the residual genetic record that can be found in historical and archaeological samples and has been successfully retrieved from archaeological sources, such as skin, teeth, soil, museum specimens, coprolites, calcified dental plaque, and bones
(Tsangaras and Greenwood, 2012; Anastasiou and Mitchell, 2013; Burrell et al., 2015). By obtaining and sequencing aDNA, researchers can test evolutionary hypotheses with actual ancestral information from a wide variety of organisms (including plants, animals, and microorganisms) and provide critical insights into their evolutionary histories (Drancourt and Raoult, 2005; Roberts and Ingham, 2008; Burrell et al., 2015). There are a number of inherent complications when working with aDNA, including the damage and fragmentation of aDNA molecules, reduced endogenous DNA content from the organism of interest, and contamination of the samples by either modern or aDNA from other sources (Willerslev and Cooper, 2005; Tsangaras and Greenwood, 2012; Carpenter et al., 2013). Therefore, validation of the results from aDNA is critical and requires the strict implementation of certain basic standards, including the use of dedicated work areas, implementation of negative template controls, proper molecular behavior of DNA fragments, originality and consistency of the sequences, and reproducibility from different extracts of the sample in independent laboratories when using single gene analyses (Cooper and Poinar, 2000; Roberts and Ingham, 2008; Sarkissian et al., 2015). Additional validation may be required in certain circumstances, especially during palaeomicrobiological analysis; this includes sample decontamination, extraction blank control assessment, neighboring sample processing, and contaminant filtering (Weyrich et al., 2015). For example, aDNA studies that use next generation sequencing (NGS) can also assess the level of modern microbial DNA contamination within their extracts (Key et al., 2017; Weyrich et al., 2019). Ancient DNA research had a turbulent start due to these limitations, but the emergence of new DNA sequencing technologies and the application of more stringent standards have allowed researchers to directly examine how organisms adapt and evolve over time (Tsangaras and Greenwood, 2012; Hagelberg et al., 2015; Sarkissian et al., 2015). Nevertheless, the analysis of data generated with these new sequencing technologies also came with inherent issues and challenges, particularly in the study of ancient microbes.

Originally embedded in paleopathology from ancient human fossil remains, early palaeomicrobiology studies relied on morphological approaches and the use of basic biomolecular techniques (i.e., microscopy and immunodetection assays) to examine ancient samples (Swain, 1969; Tran et al., 2011). For example, Dobney and Brothwell (1986) performed one of the first microscopy-based explorations of ancient human-associated microbes on archaeological dental calculus in the late 1980s. Aided by scanning electron microscopy (SEM), they showed the presence of calcified rod shaped microorganisms along with other plant and animal tissues in preserved dental plaque (Dobney and Brothwell, 1986). Fornaciari and Marchetti (1986) and Fornaciari et al. (1989) also identified the presence of ancient pathogens in Italian mummies using immunochemical studies. Later, the invention of the polymerase chain reaction (PCR) drastically improved the ability of researchers to identify and examine ancient microbes via DNA amplification. This enabled researchers to minimally explore the genetics of ancient microbes by screening for specific DNA sequences without the need to culture. While the bulk of early PCR literature 
is expansive, key studies moved our understanding of ancient pathogens forward. For example, Spigelman and Lemma (1993) were able to use PCR to identify the presence of Mycobacterium tuberculosis DNA sequences in bone remains for the first time, allowing them to confirm the suspected diagnoses in ancient samples. This approach provided some power to identify specific microorganisms and trace their relationships with modern day taxa. However, PCR-based techniques are highly sensitive to contamination and can led to erroneous conclusions (Drancourt and Raoult, 2005; Roberts and Ingham, 2008). Several inaccurate publications arose from erroneous PCR results and brewed mistrust in the aDNA field (Fischman, 1995; Yousten and Rippere, 1997; Cooper and Poinar, 2000; Hazen and Roedder, 2001), highlighting the need to increase validation standards and develop more sensitive methods. At the end of the last decade, amplicon-based metagenomic approaches and NGS methods emerged as means to improve identifications and explore broader range of microbes, revolutionize palaeomicrobiology again. Whole genome shotgun metagenomics approaches performed by implementing new sequencing techniques at the time, such as Illumina 'sequencing by synthesis' technology, again provided improved efficiencies. The massively parallelized short read sequencing lengths provided by Illumina were a perfect match for the degraded nature of short aDNA fragments. This technology represented a revolution in sequence output and allowed researchers to complete detailed analyses of nearly whole genome sequences of ancient pathogens (e.g., Yersinia pestis, Mycobacterium tuberculosis, M. leprae, Tanerella forsythia, Brucella melitensis, Helicobacter pylori) (as reviewed in Tsangaras and Greenwood, 2012).

High-throughput DNA sequencing approaches greatly extended PCR methods and made the examination of a whole ancient microbial community possible. For example, NGS shotgun sequencing was used to explore microbial functional profiles and diversity of paleofeces (coprolites) (Tito et al., 2008). The ancient fecal samples showed resemblances with modern feces and gut microbiomes. However, there was an unexpected increase in diversity in ancient coprolites compared to modern samples, providing insight into the effects of geographic, temporal, and natural selection on ancient human microbiomes. Subsequently, whole-genome shotgun sequencing was applied to ancient permafrost samples, identifying a diverse and abundant array of ancient soil taxa and providing insight into the functional profiles of ancient soil microorganisms (Yergeau et al., 2010). Metagenomic approaches, such as DNA metabarcoding, have also been applied to explore the diversity of bacteria present in and on ancient skeletons (Adler et al., 2013; Warinner et al., 2014). Metabarcoding of calcified dental plaque (calculus; i.e., a preserved oral bacteria biofilm present in ancient teeth) revealed major alterations in the overall composition of oral microbial communities through time that were associated with historical, cultural, and dietary revolutions (Adler et al., 2013). Changes in the presence of two specific oral pathogens, Streptococcus mutans and Porphyromonas gingivalis, were also apparent. Despite the use of metabarcoding for targeted questions, this approach can produce microbial community compositions that are biased due to DNA fragment length and GC content (Ziesemer et al., 2015).
Therefore, metagenomic shotgun sequencing was applied to reconstruct human microbiota and retrieve bacterial genomes (Warinner et al., 2014; Rasmussen et al., 2015; Weyrich et al., 2017) or reconstruct non-bacterial DNA in microbiome samples (Warinner et al., 2014). Despite the typically smaller size and number of archaeological samples, these studies have revealed the potential of metagenomic sequencing approaches to examine the evolution of microbial organisms, both individually and as a community. These studies have also provided insights into large alterations in human health, behavior, and culture through time, even if these changes were not linked to the presence or absence of a single pathogen, but rather collections of commensal microbial species.

Following the increased accessibility of NGS technology, hybridization capture or enrichment methods were designed and employed to examine ancient microbes. This approach involves creating RNA or DNA 'bait' sequences that are used to 'fish out' sequences of interest. These methods markedly extended the ability to obtain genomic information from a single species present within a complex 'soup' of bacterial and environmental DNA (Riesenfeld et al., 2004). Draft genome sequences have been reconstructed using hybridization capture from at least four key ancient bacterial pathogens, including Vibrio cholerae, Yersinia pestis, Mycobacterium tuberculosis, and Mycobacterium leprae (Bos et al., 2011, 2014; Schuenemann et al., 2013; Devault et al., 2014; Wagner et al., 2014). Whole genome comparisons of ancient microbial pathogens can be used to infer complex population dynamics, investigate environmental and host-pathogen interactions, track the origins and eruptions of past epidemics, and test hypotheses about the evolution of virulence through episodes of selection and extinction (Bryant et al., 2012; Vågene et al., 2018; Spyrou et al., 2019). In the following section, we summarize some of the most relevant research on these ancient pathogens, assess approaches that have been used for the study of their genomic evolution, and examine how future studies may continue to strengthen the field of palaeomicrobiology.

\section{PALAEOMICROBIOLOGY: FROM GENES TO GENOMES}

\section{Yersinia pestis: The Infectious Agent of Ancient Plagues}

Throughout history, at least three large "plague" pandemics were recorded: the First Pandemic, also known as the Plague of Justinian in the mid-6th century; the Second Plague pandemic, including the Black Death and the Great Plague of London over the 14th and 18th centuries; and the Third Pandemic, over the 19th and 20th centuries. Artistic and written documentation suggested a common etiological agent based on the descriptions of symptoms; however, direct evidence was only available for the most recent plague pandemic, where Yersinia pestis was identified as the causative agent of the disease by Alexandre Yersin (Zietz and Dunkelberg, 2004). The first retrospective diagnosis of skeletal remains from the Black Death (BD) used 
PCR and primers specific for $Y$. pestis to amplify and sequence individual aDNA fragments from the teeth of people suspected to have died of plague (Drancourt et al., 1998; Drancourt and Raoult, 2005). Although this study seemed to confirm Y. pestis as the pathological agent of the $\mathrm{BD}$, some studies challenged the results, as $Y$. pestis could not be amplified from plague victims following stringent aDNA protocols (Gilbert et al., 2004). To settle the debate, new attempts were made to obtain $Y$. pestis from plague specimens using NGS approaches (Bos et al., 2011; Schuenemann et al., 2011). These results were performed in two separate labs and followed strict validation guidelines to demonstrate aDNA authenticity. Using hybridization capture and enrichment for sequences similar to modern $Y$. pestis strains, both teams were able to retrieve and reconstruct the ancient genomic sequence of $Y$. pestis from plague victims, finally proving that this pathogen was one of the infectious agents of the BD.

Similarly, the etiology of the Justinianic Plague was debated for several years until an aDNA study was able to identify $Y$. pestis as the causative agent (Harbeck et al., 2013). Later, a low-coverage whole-genome sequence of a Justinianic strain from Southern Germany (Wagner et al., 2014) allowed the first comparison of several ancient genome sequences involved in different pandemic events. A phylogenetic analysis from these strains showed that the lineage responsible for the Justinianic outbreak was distinct from the lineages in the Second and Third Pandemics and was placed between two extant Chinese strains recovered from rodents. These results were recently confirmed with a high-coverage whole-genome sequence from a different burial (Feldman et al., 2016). Mutations were identified that could have influenced the infectivity of the Justinianic strain; however, the high-coverage genome identified a number of false positive SNPs that were reported in the previous low-coverage genome, highlighting the advantages of higher coverage sequences and the use of quality criteria to confirm the authenticity of reported substitutions. Keller et al. (2019) took a conservative approach to assay mutations in low-coverage genomes recovered from a wide-range of first pandemic genomes across Europe, examining the micro-diversity present in strains at the time. The origins of other pandemics have also now been identified; for example, the origin of the Black Death during the Second European Pandemic was traced back to Eastern Europe, although the molecular mechanisms of virulence were observed to be similar between pandemics (Spyrou et al., 2019). Further, Rasmussen et al. (2015) applied a unique approach, utilizing a metagenomic sequencing analysis method of deeply sequenced human genomic data to obtain $Y$. pestis genomes from teeth of Late Neolithic/Bronze Age humans (5,000-3,500 yBP) and explore the earlier origins of this disease. This study showed that ancient $Y$. pestis strains were already infecting ancient human populations at least 3,000 years earlier than the first recorded pandemic; however, these ancestral strains lacked many of the key virulence genes required to infect humans today and that were present in the strains from the three plague pandemics (Rasmussen et al., 2015). Further research was able to describe the virulence factors present in ancient strains, as well as specifically the bubonic form of the pathogen, and further supported the origins of plague in Europe to the Bronze Age ( 3,000 yBP; Spyrou et al., 2018), providing key insights into the evolutionary processes behind the high pathogenicity of this organism.

The studies on $Y$. pestis clearly demonstrated the effectiveness of hybridization capture/enrichment techniques in ancient microbial DNA studies. For the first time, researchers were able to trace bacterial evolution temporally and geographically in ancient civilizations, and we now have detailed maps and information about how past pandemics originated and moved across Europe. These studies represented the first successful approaches to sequencing ancient microbial genomes and revealed the potential of ancient genomic studies for understanding how bacteria co-evolved alongside humans. Furthermore, the latest studies highlight the power of metagenomic sequencing approaches and mining deeply sequenced human specimens as a novel source of ancient microbial DNA. Future studies can also likely examine the presence of $Y$. pestis outside of Europe; for example, exploring these strains in non-human mammals or insect vectors would also be an avenue to pursue to investigate host-adaptation and how its interactions with humans have shaped its evolutionary history.

\section{Mycobacterium tuberculosis: The Pathogenic Agent of TB}

Mycobacterium tuberculosis is one of the most prevalent pathogens in human history (Müller et al., 2014) and remains the second largest cause of infectious disease deaths even today (Ottini and Falchetti, 2010; Dabernat et al., 2014). Along with other genetically similar Mycobacterium species, collectively known as the Mycobacterium tuberculosis complex (MTBC), it is the predominant etiological agent in the development of tuberculosis (TB). M. tuberculosis is the most widely studied pathogen in palaeomicrobiology (Zink et al., 2007), as it has been identified in hundreds of ancient individuals from various geographical regions and across several historical periods.

Mycobacterium tuberculosis was the first ancient bacterial pathogen to be studied using biomolecular methods. Initial palaeomicrobiological research on $M$. tuberculosis concentrated on the identification of the pathogen via PCR within ancient individuals who displayed osteological damage indicative of tuberculosis (Spigelman and Lemma, 1993; Tsangaras and Greenwood, 2012). Early PCR amplification studies focused on the identification of ribosomal proteins and insertion sequences specific to MTBC, and further characterization was performed using spoligotyping (spacer oligotyping (Taylor et al., 1999; Zink et al., 2002, 2007; Fletcher et al., 2003). However, these aDNA results were criticized for their unsuitability for phylogenetic analysis, poor reproducibility, and environmental contamination (Wilbur et al., 2009; Müller et al., 2014). More appropriate molecular approaches have since been applied, such as PCR methodologies to target single nucleotide polymorphisms (SNPs) and large sequence polymorphisms (LSPs) that provide power to infer phylogenetic relationships among ancient and modern samples (Bouwman et al., 2012; Müller et al., 2014).

PCR evidence of ancient M. tuberculosis was obtained from several prehistoric samples (before 3,000 BCE) (Salo et al., 1994; Nerlich et al., 1997; Crubézy et al., 1998; Hershkovitz et al., 2008), 
and suggested a long-term co-occurrence of the pathogen and humans. Most of these studies characterized a few loci within MTBC and provided evidence of the emergence of certain TB strains through time. However, they failed to provide information about particular genomic changes that differentiate specific strains or pathogenicity traits (Zink et al., 2007). Further, some loci utilized as markers of the MTBC, such as the insertional sequence IS6110, were widely used in ancient palaeomicrobiology studies (Tsangaras and Greenwood, 2012) and have since been shown to be conserved in both the human-infecting lineages of MTBC and soil isolates within the Mycobacterium family, making identification from buried ancient samples dubious (Wilbur et al., 2009; Müller et al., 2016). In light of this, hybridization enrichment techniques have been utilized to obtain whole genomic information to identify the origins of M. tuberculosis and to examine its recent history.

Ancient genomes from Mycobacterium species present a lower-than-average damage pattern among all the ancient bacterial genomes studied to date. This has been attributed to a robust cell wall and high G-C content which may help limit bacterial DNA degradation by protecting and stabilizing DNA molecules (Zink et al., 2002; Hershkovitz et al., 2008; Tsangaras and Greenwood, 2012). Recent studies have expanded the analysis of ancient $M$. tuberculosis to examine human migration and demographic changes by analyzing DNA sequences from a variety of geographical areas and across different times (Bouwman et al., 2012; Darling et al., 2014). While previous studies amplified a limited number of markers, new studies targeted multiple loci or whole genomes from multiple samples to obtain adequate resolution and disentangle complex relationships and migration histories. NGS analysis and enrichment capture methods improved phylogenetic resolution, allowing researchers to answer more complex questions, such as the origin of tuberculosis in ancient archaeological samples from the Americas (Bos et al., 2014). Whole genome sequences of modern and ancient M. tuberculosis genomes from South America and Europe revealed that South American human TB isolates were most closely related to TB strains from seals. This finding suggests that early South American TB strains may have resulted from a zoonotic transmission event, followed by a possible dispersal throughout humans in the Americas (Bos et al., 2014).

Research on ancient M. tuberculosis reflects the evolution of the field of palaeomicrobiology, from the single gene identification via PCR to whole genome reconstruction using NGS technologies. Ancient TB research has also provided insight into the dangers of assessing partial genomic sequences without proper environmental controls and highlights the need to consider mixtures of multiple related species within the same sample (e.g., environmental and human-associated Mycobacterium). Despite this, whole genome sequences have elucidated the evolutionary history, origins, and migrations of modern lineages. Further, whole genome sequences from ancient and modern $M$. tuberculosis strains, from different geographical sources and covering a large time-transect, will provide increased resolution of evolutionary events and adaptations that are elusive to our current models. Using ancient $\mathrm{TB}$ as a model system to examine specific evolutionary questions will undoubtedly improve our understanding of microbial evolution and distribution in human and animal populations throughout the world and across time.

\section{Mycobacterium leprae: The Evolution of an Obligate Intracellular Human Pathogen}

Mycobacterium leprae is the infectious agent of leprosy, a chronic disease that has likely infected humans since prehistoric times (Donoghue, 2013; Mendum et al., 2014). Although nowadays it is most commonly found in undeveloped countries outside of Europe, archaeological and historical evidence, such as the establishment of several leper colonies, indicates leprosy was endemic in the medieval Europe, until it inexplicably vanished in the 16th century while increasing its prevalence in America and Africa (Schuenemann et al., 2013; Mendum et al., 2014; Andam et al., 2016; World Health Organization [WHO], 2016). $M$. leprae is an obligate intracellular pathogen with a slow growth rate ( $\sim 14$ days generation time in humans), high genomic conservation between strains (i.e., $<0.01 \%$ difference), a high number of pseudogenes (41\% of its genome), and the loss of several housekeeping (conserved) genes (Cole et al., 2001; Monot et al., 2005; Schuenemann et al., 2013; Mendum et al., 2014). These features suggest that the $M$. leprae has undergone genome reduction or degradation similar to that reported during the evolution of other intracellular pathogens and symbionts (Cole et al., 2001; Ochman and Moran, 2001; Monot et al., 2005; Schuenemann et al., 2013). Initial palaeomicrobiological studies used PCR to characterize $M$. leprae from skeletal remains that exhibited osteological lesions indicative of leprosy (i.e., palate and nasal bone thinning) (e.g., Spigelman and Lemma, 1993); however, the majority of these studies did not comply with the criteria required for their authentication, rendering their results questionable.

Complete genomes of ancient $M$. leprae were recently recovered from medieval European samples (Schuenemann et al., 2013; Mendum et al., 2014). These studies obtained draft $M$. leprae genomes and found very few sites of differentiation in comparison to modern strains. In addition to following the basic guidelines for authentication of aDNA, ancient human mitochondrial DNA was also obtained by enrichment as an additional control for their authenticity. While the recovered mtDNA had distinctive damage patterns consistent with aDNA, the aDNA from $M$. leprae showed much lower levels of damage, raising further questions about decay kinetics of DNA in thickouter-walled Mycobacterium species. Phylogenetic analyses of the ancient strains found them to cluster within a group containing modern Near East and Central Asia strains (Branch 2), as well as a group containing American strains and previously reported ancient European samples from a later period (Branch 3 ). This suggests that ancient strains from Branch 2 and 3 cooccurred in Europe, but eventually the Near Eastern and Asian strains were replaced by Branch 3, which later spread to the Americas (Schuenemann et al., 2013; Mendum et al., 2014). There also appeared to be little to no genetic evidence for 
virulence reduction in modern compared to ancient $M$. leprae. This is a critical finding and contradicts hypotheses that the declining incidence of leper cases in Europe through time was due to genomic changes in the pathogen. Instead, the reduction was likely caused by alternative factors, such as altered living conditions, changes in human immunity, novel protective factors, or alterations in co-infection dynamics (Schuenemann et al., 2013; Mendum et al., 2014).

Together, modern and ancient $M$. leprae DNA comparisons show a surprisingly low level of genomic variation since the divergence of the different lineages $(\sim 3,000$ years ago). Further work should explore and compare additional whole genomic sequences of various strains of all Mycobacterium species through time to explore the unique evolutionary history of this diverse genus (Harkins and Stone, 2015). Lastly, the low genetic variation and geographical associations revealed through the use of aDNA has highlighted the influence of human migrations in the propagation of this microbe in the past, suggesting trade paths such as the Silk Road as possible origins of transmission in the medieval era (Monot et al., 2009). This shows how palaeomicrobiology can do more than confirm past diagnoses, but rather contribute to the development of new hypotheses and other fields, such as history, epidemiology, and archaeology.

\section{Vibrio cholerae: Identification of Strains Involved in Ancient Pandemic Events Through Whole Genome Sequences}

Cholera is an intestinal disease caused by infection with Vibrio cholerae. In the past 200 years, seven cholera pandemics ( $V$. cholerae serotype O1) have been recorded worldwide, which were all attributed to two biotypes, distinguishable by several phenotypic markers: classical and El Tor (Harris et al., 2012). Cholera investigations based on disease etiology of early epidemics suggest that the $\mathrm{O} 1$ classical biotype may have been dominant before the last century. To test this hypothesis, Devault et al. (2014) reconstructed a near complete genome of an ancient $V$. cholerae sampled from a 19th-century preserved intestine of a patient deceased during the second cholera pandemic. This study identified the ancient strain as a "classical" biotype (serotype O1), confirming previous speculations that earlier pandemic events were caused by this strain (Devault et al., 2014). Whole genome sequence comparisons between modern and ancient strains also revealed high levels of genomic conservation, suggesting that the evolution of the modern pathogen has been under selective constraint during the past two centuries. However, it remains unclear how prevalent cholera was in more ancient periods.

Evidence suggests that the pathogenic strains involved in the last pandemics originated in Asia, so a more detailed exploration of ancient skeletons from that area could provide important insights into its origins. Sequencing aDNA from other sources, such as coprolites or mummified tissues, could also help identify $V$. cholerae in ancient specimens from populations with poor medical records, and also provide contextual information on how its infections may have impacted the gut microbiota of its inhabitants. Future studies on ancient $V$. cholerae could analyze dated human genomes or microbiomes that date to cholera pandemic events to investigate if ancient human populations were similarly affected by different strains of $V$. cholerae, and if genomic changes potentially supported the origination of this human pathogen. Moreover, additional dated ancient genomes could help to establish evolutionary rates of $V$. cholerae and add a temporal dimension to the studies.

\section{Helicobacter pylori: A Model Organism for Migration and Health}

Helicobacter pylori is one of the most prevalent human-associated microorganisms and can play commensal or pathogenic roles. It is present in more than $50 \%$ of the global population, and several strains can be associated with development of chronic gastritis and gastric ulcers (Disotell, 2003; Secka et al., 2014). Modern day populations of $H$. pylori cluster into seven geographically associated prototypes, and the most common prototype in Europe (hpEurope) is known to carry a recombinant genomic sequence from Asian and African prototypes (Secka et al., 2014). Due to its long association with humans ( $\sim 100,000$ years), wide global dispersal, and high sequence diversity, this microorganism has been used to trace past human migrations (Falush et al., 2003). Genomic sequences from ancient $H$. pylori from the "Iceman" (a 5,300-year-old European glacial mummy) were retrieved using hybridization capture enrichment (Maixner et al., 2016). Surprisingly, the genomic sequences of the ancient $H$. pylori resembled the Asian prototype, suggesting a migration of the African strain into Europe some time after 5,300 BP. The researchers also assessed the potential impact that these bacteria had in the ancient human gut and identified 22 proteins associated with inflammatory response similar to those expressed in modern humans infected by $H$. pylori.

Due to the long association with humans and a low mortality rate from $H$. pylori infection, studies of this microorganism allow us not only to obtain insights into its evolution and pathogenicity, but also the health and migrations of ancient human populations. In studies involving $H$. pylori, the availability of well-preserved samples from ancient guts is scarce; however, similar studies could be conducted on other commensal species not present in the gut. For example, an analysis of commensal microbes present in dental calculus could provide an opportunity to identify new marker species to track human migrations (Eisenhofer et al., 2019), and examine how truly commensal isolates evolve alongside humans, in contrast to pathogens with different selective pressures.

\section{Salmonella enterica: Interactions With Domesticated Animals}

Salmonella enterica is commonly referred to as a food-borne illness that causes gastroenteritis (non-typhoidal salmonellosis) with over 93.8 million cases globally each year (Majowicz et al., 2010). However, certain S. enterica serovars, such as S. Typhi and $S$. Paratyphi, are human-specific pathogens that can cause enteric fevers (Typhoid and Paratyphoid fevers, respectively) and can have lethal consequences, both in the past and today. While over 21 million cases of Typhoid still occur annually today around the world (Crump et al., 2004), their origins 
remained poorly understood until recently (Achtman, 2016). Two aDNA studies have examined the origins of Typhoid in both the Old and New Worlds. Zhou et al. (2018) were able to compare modern $S$. enterica ser. Paratyphi C strains to a single ancient strain recovered from bones and teeth in Norway that date to 1,200 CE. Using updated genomic evolutionary rates and comparative analysis to modern strains in pigs, boars, and chickens, Zhou et al. (2018) conclude that S. Paratyphi C likely originated during porcine domestication about $\sim 4,000$ years ago in Europe. In the New World, S. Typhi was linked to a cocoliztli outbreak from a 16th century site in modern Mexico, several years after the first Europeans arrived in the region in 1511 (Vågene et al., 2018).

While these and other studies seem to suggest an Old World origin for S. Typhi (Achtman et al., 2012), deeper origins cannot be ruled out (Vågene et al., 2018). The recent study by Zhou et al. (2018) concludes that origin of $S$. Paratyphi dates back 3,428 years ago, although early genetic dating estimates still suggest that $S$. Typhi may have arisen 10,000-43,000 years ago (Roumagnac et al., 2006). Further, little is known about the distribution of $S$. Typhi in historic and ancient times outside of Europe and where it may have arisen, especially considering its links to animal domestication. Studies examining both domesticated and non-domesticated animal microbiota may reveal commensal Salmonella strains in the past, providing insight into the evolution of this diverse genus. Further still, its presence in the New World and the potential effects, both social and biological, on New World Indigenous peoples needs further exploration; for example, understanding how resistance or survival of $S$. Paratyphi influenced downstream immune responses or microbiota may be critical to better understanding Indigenous health in the Americas (Skelly et al., 2018).

\section{Paleomicrobiological Examinations of Non-bacterial Species}

Recently, paleomicrobiological tools have been applied to studies beyond bacteria to include viruses, parasites, and fungi, both from humans, animals, and the environment. Ancient viruses have emerged as accessible aDNA targets to better understand the origins of human disease in real-time. For example, the genome of the Variola virus, which causes small pox, was recovered both from 20th century strains and a child mummy from the middle of the 17th century (Duggan et al., 2016), suggesting that much of the variola viral evolution examined today has occurred in the past several hundred years (Duggan et al., 2016; Wertheim, 2017). Similar approaches were utilized to exclude a paleopathological diagnosed case of ancient smallpox (Ross et al., 2018). Additional ancient viral studies have explored the much deeper evolutionary history between viruses and humans, including hepatitis B (HBV) (Krause-Kyora et al., 2018; Mühlemann et al., 2018a; Ross et al., 2018) and parvovirus (Mühlemann et al., 2018b). Similar research projects are emerging in ancient parasites, namely in Plasmodium species to trace the origins of malaria. Marciniak et al. (2016) were able to verify the presence of
P. falciparum DNA from a suspected Italian malarial outbreak in 1st-2nd century CE, while Gelabert et al. (2016) connected historic European Plasmodium strains to those circulating in the Americas, suggesting that Europeans may have introduced malaria into the Americas. These studies highlight the power of aDNA to track the origins and suspected histories of all pathogens, not only bacteria.

While many of these studies have reconstructed DNA from viral or eukaryotic pathogens in historic times, researchers can now examine the deeper evolutionary history and origins of these microbes. For example, tracking the long-term rates and directionality of viral evolution in Paleolithic humans and other hominids, such as Neanderthals, is now a possibility (Weyrich et al., 2017). Ancient DNA studies of viruses in other primates would also allow us to better calibrate and understand long-term viral evolution in hominids. Tracing back the environmental origins of ancient malarial strains, perhaps from preserved mosquitos or unique environmental samples, would also be important to better trace is distribution in the ancient past. Despite the exciting new questions that can be approaches using aDNA, it is also clear that strict aDNA methodologies must be performed during ancient viral and eukaryotic studies, as in bacterial studies, as the reliability of several ancient viral studies has already been questioned in the literature (Porter et al., 2017; Duchêne and Holmes, 2018).

\section{Overall Lessons From Whole Genome Palaeomicrobiology Studies}

The current study of ancient microbial pathogens has been mainly driven by the progress and accessibility of DNA sequencing technologies and sample availability. The early use of aDNA methodologies provided the opportunity to identify ancient pathogens for the first time and add a temporal dimension to the evolutionary history of important human microbial pathogens. Early palaeomicrobiological studies also used single or a restricted number of loci and provided only limited descriptions of temporal and geographic distributions of pathogens within human populations. In some cases, early studies even mistakenly identified environmental or nonpathogenic species that shared sequence with their pathogenic counterparts (Müller et al., 2016). Further, these early studies did not provide insight into genome-wide changes that allow organisms to increase or reduce their pathogenicity and adapt to niches, nor did they allow researchers to determine where specific strains originated.

The invention of NGS technologies has had a major impact on the field of palaeomicrobiology, allowing researchers to amplify, target, and retrieve specific aDNA sequences from a variety of microorganisms and reconstruct partial or whole genomes. By comparing near-complete genomes of ancient and modern microbial pathogens, researchers have been able to describe differences between strains, interrogate the evolution and acquisition of virulence mechanisms, and the social and biological mechanisms that underpin pathogen origins. By identifying the genomic changes in pathogenic microorganisms through time, and comparing their effects on ancient and modern 
populations, we are beginning to track the origins of modern disease, trace the underlying causes of pandemics, and monitor microbial evolution in real time.

\section{THE FUTURE OF PALAEOMICROBIOLOGICAL STUDIES: NON-PATHOGENIC MICROBES}

\section{Moving Beyond Pathogens to Non-infectious, Non-lethal, and Commensal Microbial Species}

Because of their relevance to human health and the availability of the samples, the majority of palaeomicrobiological studies have concentrated on the diagnosis and identification of ancient pathogenic organisms involved in historical pandemics that typically cause acute, highly lethal diseases. However, symbiotic, non-pathogenic microorganisms also have a significant impact on human health by playing commensal or mutualistic roles. Many commensal microorganisms are evidence of a longstanding, co-evolutionary relationships; however, commensal bacteria can become opportunistic pathogens depending on the environmental conditions, albeit those conditions are poorly understood. Therefore, it is important to examine not only pathogens, but also the symbiotic microorganisms in the body and the micro-ecological context in which pathogens are successful. Infectivity and disease success can be highly influenced by competition (for similar nutritional resources or space) and cooperation between microorganisms, and this complex network of interactions has not yet been fully examined in palaeomicrobiological studies. For example, the dental caries causing pathogen, Streptococcus mutans, has competition from multiple other Streptococcus species that are routinely known to inhabit the oral cavity, but it remains unclear with other Streptococcus species were more dominant before the rise of S. mutans associated with the adoption of agriculture (Cornejo et al., 2013). For this purpose, future research should explore the connection and relationship between individual bacterial genomes of commensal species and the related microbiota to ascertain how genomic differences correlate with selective pressures or alterations in the microbial community. Correlations between the prevalence of certain microbial communities and a pathogen could provide information on disease susceptibility and a powerful new way to assess past population morbidity and health, especially in non-infectious diseases. Further still, nonlethal pathogens can provide information about the evolution of commensalism and serve as proxies to understand human interactions and movements. Examples of these endemic oral microbes include Streptococcus, Neisseria, and Actinomyces species (Avila et al., 2009). Future microbial community analysis may also reveal other species that would be better targets to answer these questions.

\section{Examination of Non-bacterial Species}

Future palaeomicrobiology studies should include further research on non-bacterial microorganisms. Whole-genome sequences of ancient yeasts, viruses, fungi, and parasites are emerging, demonstrating how aDNA can provide, as in the case of bacterial pathogens, important insights into their evolution, both within humans and the environment. For example, the study of ancient yeast is an important issue, as they have played critical roles in disease development in humans, such as dental decay (Brighenti et al., 2014; Koo and Bowen, 2014), as well as in the fermentation and preservation of food products (Gibbons and Rinker, 2015). Future efforts could be applied to understand the impact of human selection and interaction on fermentation and preservation yeasts through time. An important advantage of yeasts is their ability to form spores, which are resistant to a variety of environmental stresses and may provide unique opportunities for preservation, although new extraction methodologies will likely need to be developed, as has been done for many other species (Shapiro et al., 2019). Furthermore, the interaction of human-associated yeasts and their products, such as fermentation, could have had an identifiable impact on human evolution and alterations of the human microbiome.

\section{Incorporation of Unique Sample Types}

Two key human tissues have been utilized in many of the studies described in this review - bones and teeth. However, recent aDNA applications included microbiome containing specimens, such as dental calculus or coprolites, and have expanded our view of appropriate ancient specimens for palaeomicrobiological analysis (Tito et al., 2008; Adler et al., 2013). Further still, some recent samples have examined unique human-associated samples, such as calcified abscesses or kidney stones (Kay et al., 2014; Devault et al., 2017). Further still, well-preserved soft-tissue samples have also been shown to contain human microbiota, such as the "Iceman" mummy, although these are notably scarce. As our ability to accurately identify ancient microbes expands, novel sample types should be explored as sources of ancient bacteria, including pathogens, non-lethal pathogenic species, or commensal species. Unique sample types may include different human tissues, such as hair (Tobler et al., 2017), human associated archaeological materials, such as pots, ochre (Lenehan et al., 2017), or pitch (Jensen et al., 2019), or even humanassociated microbes preserved in environmental specimens, such as ice (Turney et al., 2020), calcium carbonate (Frisia et al., 2017), or marine and terrestrial soils (Tobler et al., 2017). The use of new specimens will certainly further our understanding of the origins and evolution of many human-associated microbes, although attention to proper authentication criteria must be considered in all cases. Minimally, the integration of unique sample types will increase the available geographic and temporal range of ancient microbial genomes.

\section{Assessment of Non-human Associated Microbes}

Most of the palaeomicrobiological studies to date have been conducted on human samples. However, domestic and wild animals are an important source of diseases, and many ancient pathogens may have been transferred between animals and humans, especially during the Neolithic Revolution when 
agricultural practices including animal husbandry were adapted (Wolfe et al., 2007). Where available, conserved remains from animals should be explored for pathogens. Plague is a good example of cases where animals played an important role in the transmission of disease to humans, although the roles that zoonotic vectors played in other ancient diseases remains unknown. Investigations into human pathogens with animal or insect reservoirs would also provide key information about pathogen-host co-evolution. As we expect rates of evolution to be variable across different microbes and/or strains in specific hosts, clear attention to the calculation of evolutionary rates and how these are influenced by mis-mapping or contamination will be key (Key et al., 2017; Bos et al., 2019). Studies exploring animal microbiomes could also provide information into the health and morbidity of ancient animals, help define their interactions with humans, and even provide details about their domestication, migration, and adaptation to past environments.

\section{CONCLUSION}

The field of palaeomicrobiology has been revolutionized by NGS technologies, moving away from retrospective, single-gene diagnoses to whole genome analyses. Whole ancient genome sequences provide greater resolution to unequivocally identify the causes of ancient diseases and to obtain important insights into the evolution of pathogens, giving way to more complex hypotheses, models, and conclusions. Ancient DNA now offers the advantage to test evolutionary hypotheses across a widerange of microbes with real, time-stamped data collected from

\section{REFERENCES}

Achtman, M. (2016). How old are bacterial pathogens? Proc. Biol. Sci. 283:1836.

Achtman, M., Wain, J., Weill, F.-X., Nair, S., Zhou, Z., and Sangal, V. (2012). Multilocus sequence typing as a replacement for serotyping in Salmonella enterica. PLoS Pathog. 8:e1002776. doi: 10.1371/journal.ppat.1002776

Adler, C. J., Dobney, K., Weyrich, L. S., Kaidonis, J., Walker, A. W., and Haak, W. (2013). Sequencing ancient calcified dental plaque shows changes in oral microbiota with dietary shifts of the neolithic and industrial revolutions. Nat. Genet. 45, 450e-455e. doi: 10.1038/ng.2536

Anastasiou, E., and Mitchell, P. D. (2013). Palaeopathology and genes: investigating the genetics of infectious diseases in excavated human skeletal remains and mummies from past populations. Gene 528, 33-40. doi: 10.1016/j.gene.2013.06. 017

Andam, C. P., Worby, C. J., Chang, Q., and Campana, M. G. (2016). Microbial genomics of ancient plagues and outbreaks. Trends Microbiol. 24, 978-990. doi: 10.1016/j.tim.2016.08.004

Armbrecht, L. H., Coolen, M. J. L., Lejzerowicz, F., George, S. C., Negandhi, K., Suzuki, Y., et al. (2019). Ancient DNA from marine sediments: precautions and considerations for seafloor coring, sample handling and data generation. Earth Sci. Rev. 196:102887.

Avila, M., Ojcius, D. M., and Yilmaz, Ö (2009). The oral microbiota: living with a permanent guest. DNA Cell Biol. 28, 405-411. doi: 10.1089/dna.2009.0874

Bentley, S. D., and Parkhill, J. (2015). Genomic perspectives on the evolution and spread of bacterial pathogens. Proc. Biol. Sci. 282:20150488. doi: 10.1098/rspb. 2015.0488

Bos, K. I., Harkins, K. M., Herbig, A., Coscolla, M., Weber, N., and Comas, I. (2014). Pre-Columbian mycobacterial genomes reveal seals as a source of new world human tuberculosis. Nature 514, 494-497. doi: 10.1038/nature13591 the past. Deep co-evolutionary histories with non-pathogenic microbes need to be explored further, thus confirming, correcting or adding information uncovered in modern microbiome studies or inferred from models created with modern data. Most importantly, future palaeomicrobiological studies of past microorganisms will continue to provide invaluable insight into our own history, migrations, and evolution.

\section{AUTHOR CONTRIBUTIONS}

LA, AC, and LW conceived of the manuscript. LA and LW wrote the manuscript. LA, AC, and LW edited the final manuscript.

\section{FUNDING}

This research was funded by an Australian Research Council Discovery Early Career Fellowship Award (LW; DE150101574), Laureate Fellowship (AC; FL140100260), and an Australian Research Council Centre of Excellence award (AC and LW; CE170100015). This research is supported by an Australian Government Research Training Program (RTP) Scholarship (LA).

\section{ACKNOWLEDGMENTS}

We would like to thank the members of the Metagenomics Research Cluster at the Australian Centre for Ancient DNA for insightful discussions on this manuscript.

Bos, K. I., Kühnert, D., Herbig, A., Esquivel-Gomez, L. R., Valtueña, A. A., and Barquera, R. (2019). Paleomicrobiology: diagnosis and evolution of ancient pathogens. Annu. Rev. Microbiol. 73, 639-666. doi: 10.1146/annurev-micro090817-062436

Bos, K. I., Schuenemann, V. J., Golding, G. B., Burbano, H. A., Waglechner, N., and Coombes, B. K. (2011). A draft genome of Yersinia pestis from victims of the black death. Nature 478, 506-510. doi: 10.1038/nature10549

Bouwman, A. S., Kennedy, S. L., Müller, R., Stephens, R. H., Holst, M., and Caffell, A. C. (2012). Genotype of a historic strain of mycobacterium tuberculosis. Proc. Natl. Acad. Sci. U.S.A. 109, 18511-18516. doi: 10.1073/pnas.1209444109

Brighenti, F. L., Medeiros, A. C., Matos, B. M., Ribeiro, Z. E., and Koga-Ito, C. Y. (2014). Evaluation of caries-associated virulence of biofilms from Candida albicans isolated from saliva of pediatric patients with sickle-cell anemia. J. Appl. Oral Sci. 22, 484-489. doi: 10.1590/1678-775720130603

Bryant, J., Chewapreecha, C., and Bentley, S. D. (2012). Developing insights into the mechanisms of evolution of bacterial pathogens from whole-genome sequences. Future Microbiol. 7, 1283-1296. doi: 10.2217/fmb.12.108

Burrell, A. S., Disotell, T. R., and Bergey, C. M. (2015). The use of museum specimens with high-throughput DNA sequencers. J. Hum. Evol. 79, 35-44. doi: 10.1016/j.jhevol.2014.10.015

Carpenter, M. L., Buenrostro, J. D., Valdiosera, C., Schroeder, H., Allentoft, M. E., and Sikora, M. (2013). Pulling out the 1\%: whole-genome capture for the targeted enrichment of ancient DNA sequencing libraries. Am. J. Hum. Genet. 93, 852-864. doi: 10.1016/j.ajhg.2013.10.002

Cole, S. T., Eiglmeier, K., Parkhill, J., James, K. D., Thomson, N. R., and Wheeler, P. R. (2001). Massive gene decay in the leprosy bacillus. Nature 409, 1007-1011.

Cornejo, O. E., Lefébure, T., PavinskiBitar, P. D., Lang, P., Richards, V. P., Eilertson, K., et al. (2013). Evolutionary and population genomics of the cavity causing bacteria Streptococcus mutans. Mol. Biol. Evol. 30, 881-893. 
Cooper, A., and Poinar, H. N. (2000). Ancient DNA: do it right or not at all. Science 289:1139.

Crubézy, E., Ludes, B., Poveda, J.-D., Clayton, J., Crouau-Roy, B., and Montagnon, D. (1998). Identification of mycobacterium DNA in an Egyptian Pott's disease of 5400 years old. C. R. Acad. Sci. III 321, 941-951. doi: 10.1016/s0764-4469(99) 80009-2

Crump, J. A., Luby, S. P., and Mintz, E. D. (2004). The global burden of typhoid fever. Bull. World Health Organ. 82, 346-353.

Dabernat, H., Theves, C., Bouakaze, C., Nikolaeva, D., Keyser, C., and Mokrousov, I. (2014). Tuberculosis epidemiology and selection in an autochthonous Siberian population from the 16th-19th century. PLoS One 9:e89877. doi: 10 . 1371/journal.pone.0089877

Darling, M. I., Donoghue, H. D., Darling, M. I., and Donoghue, H. D. (2014). Insights from paleomicrobiology into the indigenous peoples of pre-colonial America - a review. Mem. Inst. Oswaldo Cruz 109, 131-139. doi: 10.1590/00740276140589

Devault, A. M., Golding, G. B., Waglechner, N., Enk, J. M., Kuch, M., and Tien, J. H. (2014). Second-pandemic strain of Vibrio cholerae from the philadelphia cholera outbreak of 1849. N. Engl. J. Med. 370, 334-340. doi: 10.1056/ NEJMoa1308663

Devault, A. M., Mortimer, T. D., Kitchen, A., Kiesewetter, H., Enk, J. M., Golding, G. B., et al. (2017). A molecular portrait of maternal sepsis from Byzantine Troy (GH Perry, Ed). eLife 6:e20983.

Disotell, T. R. (2003). Discovering human history from stomach bacteria. Genome Biol. 4:213.

Dobney, K., and Brothwell, D. (1986). Dental calculus: its relevance to ancient diet and oral ecology. in: teeth and anthropology. BAR Int. Ser. 291, 55-81.

Donoghue, H. D. (2013). Insights into ancient leprosy and tuberculosis using metagenomics. Trends Microbiol. 21, 448-450. doi: 10.1016/j.tim.2013.07.007

Drancourt, M., Aboudharam, G., Signoli, M., Dutour, O., and Raoult, D. (1998). Detection of 400-year-old Yersinia pestis DNA in human dental pulp: an approach to the diagnosis of ancient septicemia. PNAS 95, 12637-12640. doi: 10.1073/pnas.95.21.12637

Drancourt, M., and Raoult, D. (2005). Palaeomicrobiology: current issues and perspectives. Nat. Rev. Microbiol. 3, 23-35. doi: 10.1038/nrmicro1063

Duchêne, S., and Holmes, E. C. (2018). Estimating evolutionary rates in giant viruses using ancient genomes. Virus Evol. 4:vey006. doi: 10.1093/ve/vey006

Duggan, A. T., Perdomo, M. F., Piombino-Mascali, D., Marciniak, S., Poinar, D., and Emery, M. V. (2016). 17th century variola virus reveals the recent history of smallpox. Curr. Biol. 26, 3407-3412. doi: 10.1016/j.cub.2016.10.061

Eisenhofer, R., Anderson, A., Dobney, K., Cooper, A., and Weyrich, L. (2019). Ancient microbial DNA in dental calculus: a new method for studying rapid human migration events. J. Island Coast. Archaeol. 14, 149-162.

Falush, D., Wirth, T., Linz, B., Pritchard, J. K., Stephens, M., and Kidd, M. (2003). Traces of human migrations in Helicobacter pylori populations. Science 299, 1582-1585. doi: 10.1126/science.1080857

Feldman, M., Harbeck, M., Keller, M., Spyrou, M. A., Rott, A., and Trautmann, B. (2016). A high-coverage Yersinia pestis genome from a 6th-century justinianic plague victim. Mol. Biol. Evol. 33, 2911-2923.

Fischman, J. (1995). Have 25-million-year-old bacteria returned to life? Science 268, 977-977. doi: 10.1126/science.7754393

Fletcher, H. A., Donoghue, H. D., Taylor, G. M., van der Zanden, G. M., and Spigelman, M. (2003). Molecular analysis of mycobacterium tuberculosis DNA from a family of 18th century Hungarians. Microbiology 149(Pt 1), 143-151. doi: 10.1099/mic.0.25961-0

Fornaciari, G., Castagna, M., Tognetti, A., Tornaboni, D., and Bruno, J. (1989). Syphilis in a renaissance Italian mummy. Lancet 2:614. doi: 10.1016/s01406736(89)90729-0

Fornaciari, G., and Marchetti, A. (1986). Intact smallpox virus particles in an Italian mummy of sixteenth century. Lancet 2:625. doi: 10.1016/s0140-6736(86) 92443-8

Frisia, S., Weyrich, L. S., Hellstrom, J., Borsato, A., Golledge, N. R., and Anesio, A. M. (2017). The influence of antarctic subglacial volcanism on the global iron cycle during the last glacial maximum. Nat. Commun. 8:15425.

Gelabert, P., Sandoval-Velasco, M., Olalde, I., Fregel, R., Rieux, A., and Escosa, R. (2016). Mitochondrial DNA from the eradicated European Plasmodium vivax and P. falciparum from 70-year-old slides from the Ebro Delta in Spain. PNAS 113, 11495-11500. doi: 10.1073/pnas.1611017113
Gibbons, J. G., and Rinker, D. C. (2015). The genomics of microbial domestication in the fermented food environment. Curr. Opin. Genet. Dev. 35, 1-8. doi: 10.1016/j.gde.2015.07.003

Gilbert, M. T. P., Cuccui, J., White, W., Lynnerup, N., Titball, R. W., and Cooper, A. (2004). Absence of Yersinia pestis-specific DNA in human teeth from five European excavations of putative plague victims. Microbiology 150, 341-354. doi: 10.1099/mic.0.26594-0

Hagelberg, E., Hofreiter, M., and Keyser, C. (2015). Ancient DNA: the first three decades. Philos. Trans. R. Soc. Lond. B Biol. Sci. 370:20130371. doi: 10.1098/ rstb.2013.0371

Harbeck, M., Seifert, L., Hänsch, S., Wagner, D. M., Birdsell, D., and Parise, K. L. (2013). Yersinia pestis DNA from skeletal remains from the 6th Century AD reveals insights into justinianic plague. PLoS Pathog. 9:e1003349. doi: 10.1371/ journal.ppat.1003349

Harkins, K. M., and Stone, A. C. (2015). Ancient pathogen genomics: insights into timing and adaptation. J. Hum. Evol. 79, 137-149. doi: 10.1016/j.jhevol.2014.11. 002

Harris, J. B., LaRocque, R. C., Qadri, F., Ryan, E. T., and Calderwood, S. B. (2012). Cholera. Lancet 379, 2466-2476. doi: 10.1016/S0140-6736(12)60436-X

Hazen, R. M., and Roedder, E. (2001). Biogeology: how old are bacteria from the permian age? Nature 411, 155-155. doi: 10.1038/35075663

Hershkovitz, I., Donoghue, H. D., Minnikin, D. E., Besra, G. S., Lee, O. Y., and Gernaey, A. M. (2008). Detection and molecular characterization of 9000-year-old mycobacterium tuberculosis from a neolithic settlement in the eastern mediterranean. PLoS One 3:e3426. doi: 10.1371/journal.pone. 0003426

Jensen, T. Z. T., Niemann, J., Iversen, K. H., Fotakis, A. K., Gopalakrishnan, S., Vågene, et al. (2019). A 5700 year-old human genome and oral microbiome from chewed birch pitch. Nat. Commun. 10:5520. doi: 10.1038/s41467-01913549-9

Kay, G. L., Sergeant, M. J., Giuffra, V., Bandiera, P., Milanese, M., Bramanti, B., et al. (2014). Recovery of a medieval brucella melitensis genome using shotgun metagenomics (PS Keim, Ed). mBio 5:e1337-14.

Keller, M., Spyrou, M. A., Scheib, C. L., Neumann, G. U., Kröpelin, A., and Haas-Gebhard, B. (2019). Ancient Yersinia pestis genomes from across Western Europe reveal early diversification during the first pandemic (541-750). PNAS 116, 12363-12372. doi: 10.1073/pnas.18204 47116

Key, F. M., Posth, C., Krause, J., Herbig, A., and Bos, K. I. (2017). Mining metagenomic data sets for ancient DNA: recommended protocols for authentication. Trends Genet. 33, 508-520. doi: 10.1016/j.tig.2017.05.005

Koo, H., and Bowen, W. H. (2014). Candida albicans and Streptococcus mutans: a potential synergistic alliance to cause virulent tooth decay in children. Future Microbiol. 9, 1295-1297. doi: 10.2217/fmb.14.92

Krause-Kyora, B., Susat, J., Key, F. M., Kühnert, D., Bosse, E., and Immel, A. (2018). Neolithic and medieval virus genomes reveal complex evolution of hepatitis B. eLife 7:e36666. doi: 10.7554/eLife.36666

Lenehan, C. E., Tobe, S. S., Smith, R. J., and Popelka-Filcoff, R. S. (2017). Microbial composition analyses by $16 \mathrm{~S}$ rRNA sequencing: a proof of concept approach to provenance determination of archaeological ochre. PLoS One 12:e185252. doi: 10.1371/journal.pone.0185252

Land, M., Hauser, L., Jun, S.-R., Nookaew, I., Leuze, M. R., and Ahn, T. H. (2015). Insights from 20 years of bacterial genome sequencing. Funct. Integr. Genomics 15, 141-161. doi: 10.1007/s10142-015-0433-4

Maixner, F., Krause-Kyora, B., Turaev, D., Herbig, A., Hoopmann, M. R., Hallows, J. L., et al. (2016). The 5300-year-old Helicobacter pylori genome of the Iceman. Science 351, 162-165. doi: 10.1126/science. aad 2545

Marciniak, S., Prowse, T. L., Herring, D. A., Klunk, J., Kuch, M., Duggan, A. T., et al. (2016). Plasmodium falciparum malaria in $1^{\text {st }}-2^{\text {nd }}$ century CE southern Italy. Curr. Biol. 26, R1220-R1222. doi: 10.1016/j.cub.2016.10.016

Majowicz, S. E., Musto, J., Scallan, E., Angulo, F. J., Kirk, M., O’Brien, S. J., et al. (2010). The global burden of nontyphoidal Salmonella gastroenteritis. Clin. Infect. Dis. 50, 882-889.

Mendum, T. A., Schuenemann, V. J., Roffey, S., Taylor, G. M., Wu, H., Singh, P., et al. (2014). Mycobacterium leprae genomes from a British medieval leprosy hospital: towards understanding an ancient epidemic. BMC Genomics 15:270. doi: 10.1186/1471-2164-15-270 
Monot, M., Honoré, N., Garnier, T., Araoz, R., Coppée, J. Y., Lacroix, C., et al. (2005). On the origin of leprosy. Science 308, 1040-1042. doi: 10.1126/science/ 1109759

Monot, M., Honoré, N., Garnier, T., Zidane, N., Sherafi, D., Paniz-Mondolfi, A., et al. (2009). Comparative genomic and phylogeographic analysis of Mycobacterium leprae. Nat. Genet. 41, 1282-1289. doi: 10.1038/ng.477

Mühlemann, B., Jones, T. C., Damgaard, P., de, B., Allentoft, M. E., Shevnina, I., et al. (2018a). Ancient hepatitis B viruses from the Bronze age to the medieval period. Nature 557, 418-423. doi: 10.1038/s41586-018-0097-z

Mühlemann, B., Margaryan, A., Damgaard, P., de, B., Morten, A. E., Lasse, V., et al. (2018b). Ancient human parvovirus B19 in Eurasia reveals its long-term association with humans. PNAS 115, 7557-7562. doi: 10.1073/pnas.1804921115

Müller, R., Roberts, C. A., and Brown, T. A. (2014). Genotyping of ancient mycobacterium tuberculosis strains reveals historic genetic diversity. Proc. $R$. Soc. B 281:20133236. doi: 10.1098/rspb.2013.3236

Müller, R., Roberts, C. A., and Brown, T. A. (2016). Complications in the study of ancient tuberculosis: presence of environmental bacteria in human archaeological remains. J. Archaeol. Sci. 68, 5-11. doi: 10.1016/j.jas.2016.03.002

Nerlich, A. G., Haas, C. J., Zink, A., Szeimies, U., and Hagedorn, H. G. (1997). Molecular evidence for tuberculosis in an ancient Egyptian mummy. Lancet 350:1404. doi: 10.1016/s0140-6736(05)65185-9

Ochman, H., and Moran, N. A. (2001). Genes lost and genes found: evolution of bacterial pathogenesis and symbiosis. Science 292, 1096-1099. doi: 10.1126/ science. 1058543

Ottini, L., and Falchetti, M. (2010). [When history meets molecular medicine: molecular history of human tuberculosis]. Med. Secoli. 22, 611-632.

Porter, A. F., Duggan, A. T., Poinar, H. N., and Holmes, E. C. (2017). Comment: characterization of two historic smallpox specimens from a Czech museum. Viruses 9:276. doi: 10.3390/v9100276

Rasmussen, S., Allentoft, M. E., Nielsen, K., Orlando, L., Sikora, M., Sjögren, K. G., et al. (2015). Early divergent strains of Yersinia pestis in Eurasia 5,000 years ago. Cell 163, 571-582. doi: 10.1016/j.cell.2015.10.009

Reddy, T. B. K., Thomas, A. D., Stamatis, D., Bertsch, J., Isbandi, M., and Jansson, J. (2014). The genomes online database (GOLD) v.5: a metadata management system based on a four level (meta)genome project classification. Nucl. Acids Res. 43, D1099-D1106.

Riesenfeld, C. S., Schloss, P. D., and Handelsman, J. (2004). METAGENOMICS: genomic analysis of microbial communities. Annu. Rev. Genet. 38, 525-552. doi: 10.1146/annurev.genet.38.072902.091216

Roberts, C., and Ingham, S. (2008). Using ancient DNA analysis in palaeopathology: a critical analysis of published papers, with recommendations for future work. Int. J. Osteoarchaeol. 18, 600-613. doi: 10.1002/oa.966

Ross, Z. P., Klunk, J., Fornaciari, G., Giuffra, V., Duchêne, S., and Duggan, A. T. (2018). The paradox of HBV evolution as revealed from a 16th century mummy. PLoS Pathog. 14:e1006750. doi: 10.1371/journal.ppat.1006750

Roumagnac, P., Weill, F.-X., Dolecek, C., Baker, S., Brisse, S., and Chinh, N. T. (2006). Evolutionary history of Salmonella typhi. Science 314, 1301-1304.

Salo, W. L., Aufderheide, A. C., Buikstra, J., and Holcomb, T. A. (1994). Identification of mycobacterium tuberculosis DNA in a pre-Columbian Peruvian mummy. PNAS 91, 2091-2094. doi: 10.1073/pnas.91.6.2091

Sarkissian, C. D., Allentoft, M. E., Ávila-Arcos, M. C., Barnett, R., Campos, P. F., and Cappellini, E. (2015). Ancient genomics. Philos. Trans. R. Soc. Lond. B Biol. Sci. 370:20130387. doi: 10.1098/rstb.2013.0387

Schloss, P. D., and Handelsman, J. (2005). Metagenomics for studying unculturable microorganisms: cutting the Gordian knot. Genome Biol. 6:229.

Schuenemann, V. J., Bos, K., DeWitte, S., Schmedes, S., Jamieson, J., and Mittnik, A. (2011). Targeted enrichment of ancient pathogens yielding the pPCP1 plasmid of Yersinia pestis from victims of the black death. Proc. Natl. Acad. Sci. U.S.A. 108, E746-E752. doi: 10.1073/pnas.1105107108

Schuenemann, V. J., Singh, P., Mendum, T. A., Krause-Kyora, B., Jäger, G., and Bos, K. I. (2013). Genome-wide comparison of medieval and modern Mycobacterium leprae. Science 341, 179-183. doi: 10.1126/science.123 8286

Secka, O., Moodley, Y., Antonio, M., Berg, D. E., Tapgun, M., and Walton, R. (2014). Population genetic analyses of Helicobacter pylori isolates from Gambian adults and children. PLoS One 9:e109466. doi: 10.1371/journal.pone. 0109466

Shapiro, B., Barlow, A., and Heintzman, PD. (Eds). (2019). Ancient DNA: Methods and Protocols. Totowa, NJ: Humana Press.
Skelly, E., Kapellas, K., Cooper, A., and Weyrich, L. S. (2018). Consequences of colonialism: a microbial perspective to contemporary Indigenous health. Am. J. Phys. Anthropol. 167, 423-437. doi: 10.1002/ajpa.23637

Spigelman, M., and Lemma, E. (1993). The use of the polymerase chain reaction (PCR) to detect mycobacterium tuberculosis in ancient skeletons. Int. J. Osteoarchaeol. 3, 137-143. doi: 10.1002/oa.1390030211

Spyrou, M. A., Keller, M., Tukhbatova, R. I., Scheib, C. L., Nelson, E. A., and Andrades Valtueña, A. (2019). Phylogeography of the second plague pandemic revealed through analysis of historical Yersinia pestis genomes. Nat. Commun. 10:4470. doi: 10.1038/s41467-019-12154-0

Spyrou, M. A., Tukhbatova, R. I., Wang, C.-C., Valtueña, A. A., Lankapalli, A. K., Kondrashin, V. V., et al. (2018). Analysis of 3800-year-old Yersinia pestis genomes suggests Bronze Age origin for bubonic plague. Nat. Commun. 9:2234.

Swain, F. M. (1969). Paleomicrobiology. Annu. Rev. Microbiol. 23, 455-472.

Taylor, G. M., Goyal, M., Legge, A. J., Shaw, R. J., and Young, D. (1999). Genotypic analysis of mycobacterium tuberculosis from medieval human remains. Microbiology 145, 899-904. doi: 10.1099/13500872-145-4-899

Tito, R. Y., Macmil, S., Wiley, G., Najar, F., Cleeland, L., and Qu, C. (2008). Phylotyping and functional analysis of two ancient human microbiomes. PLoS One 3:e3703. doi: 10.1371/journal.pone.0003703

Tobler, R., Rohrlach, A., Soubrier, J., Bover, P., Llamas, B., Tuke, J., et al. (2017). Aboriginal mitogenomes reveal 50,000 years of regionalism in Australia. Nature $544,180-184$.

Tran, T.-N.-N., Aboudharam, G., Raoult, D., and Drancourt, M. (2011). Beyond ancient microbial DNA: nonnucleotidic biomolecules for paleomicrobiology. BioTechniques 50, 370-380. doi: 10.2144/000113689

Tsangaras, K., and Greenwood, A. D. (2012). Museums and disease: using tissue archive and museum samples to study pathogens. Ann. Anat. 194, 58-73. doi: 10.1016/j.aanat.2011.04.003

Turney, C. S. M., Fogwill, C. J., Golledge, N. R., McKay, N. P., van Sebille, E., Jones, R. T., et al. (2020). Early Last Interglacial ocean warming drovesubstantial ice mass loss from Antarctica. Proc Natl. Acad. Sci. U.S.A. 117, 3996-4006.

Vågene, ÅJ., Herbig, A., Campana, M. G., Warinner, C., Spyrou, M. A., and Valtueña, A. A. (2018). Salmonella enterica genomes from victims of a major sixteenth-century epidemic in Mexico. Nat. Ecol. Evol. 2, 520-528. doi: 10.1038/ s41559-017-0446-6

Wagner, D. M., Klunk, J., Harbeck, M., Devault, A., Waglechner, N., and Sahl, J. W. (2014). Yersinia pestis and the plague of justinian 541-543 AD: a genomic analysis. Lancet Infect. Dis. 14, 319-326. doi: 10.1016/S1473-3099(13)70323-2

Warinner, C., Rodrigues, J. F. M., Vyas, R., Trachsel, C., Shved, N., and Grossmann, J. (2014). Pathogens and host immunity in the ancient human oral cavity. Nat. Genet. 46, 336-344. doi: 10.1038/ng.2906

Wertheim, J. O. (2017). Viral evolution: mummy virus challenges presumed history of smallpox. Curr. Biol. 27, R119-R120. doi: 10.1016/j.cub.2016.12.008

Weyrich, L. S., Dobney, K., and Cooper, A. (2015). Ancient DNA analysis of dental calculus. J. Hum. Evol. 79, 119-124. doi: 10.1016/j.jhevol.2014.06.018

Weyrich, L. S., Duchene, S., Soubrier, J., Arriola, L., Llamas, B., Breen, J., et al. (2017). Neanderthal behaviour, diet, and disease inferred from ancient DNA in dental calculus. Nature 544, 357-361.

Weyrich, L. S., Farrer, A. G., Eisenhofer, R., Arriola, L. A., Young, J., and Selway, C. A. (2019). Laboratory contamination over time during low-biomass sample analysis. Mol. Ecol. Resour. 19, 982-996. doi: 10.1111/1755-0998.13011

Wilbur, A. K., Bouwman, A. S., Stone, A. C., Roberts, C. A., Pfister, L. A., and Buikstra, J. (2009). Deficiencies and challenges in the study of ancient tuberculosis DNA. J. Archaeol. Sci. 36, 1990-1997. doi: 10.1016/j.jas.2009.05. 020

Willerslev, E., and Cooper, A. (2005). Review paper. Ancient DNA. Proc. R. Soc. B 272, 3-16. doi: 10.1098/rspb.2004.2813

Wolfe, N. D., Dunavan, C. P., and Diamond, J. (2007). Origins of major human infectious diseases. Nature 447, 279-283. doi: 10.1038/nature05775

World Health Organization [WHO] (2016). WHO | Global Leprosy Update, 2015: Time for Action, Accountability and Inclusion. Available online at: http//www. who.int/lep/resources/who_wer9135/en/ (accessed October 18, 2016).

Yergeau, E., Hogues, H., Whyte, L. G., and Greer, C. W. (2010). The functional potential of high Arctic permafrost revealed by metagenomic sequencing, qPCR and microarray analyses. ISME J. 4, 1206-1214. doi: 10.1038/ismej.2010.41

Yousten, A. A., and Rippere, K. E. (1997). DNA similarity analysis of a putative ancient bacterial isolate obtained from amber. FEMS Microbiol. Lett. 152, 345-347. doi: 10.1111/j.1574-6968.1997.tb10450.x 
Zhou, Z., Lundstrøm, I., Tran-Dien, A., Duchêne, S., Alikhan, N. F., and Sergeant, M. J. (2018). Pan-genome analysis of ancient and modern Salmonella enterica demonstrates genomic stability of the invasive para $\mathrm{C}$ lineage for millennia. Curr. Biol. 28, 2420.e-2428.e. doi: 10.1016/j.cub.2018. 05.058

Ziesemer, K. A., Mann, A. E., Sankaranarayanan, K., Schroeder, H., Ozga, A., Brandt, B. W., et al. (2015). Intrinsic challenges in ancient microbiome reconstruction using 16S rRNA gene amplification. Sci. Rep. 5:16498.

Zietz, B. P., and Dunkelberg, H. (2004). The history of the plague and the research on the causative agent Yersinia pestis. Int. J. Hyg. Environ. Health 207, 165-178. doi: 10.1078/1438-4639-00259

Zink, A. R., Molnár, E., Motamedi, N., and Palfi, G. (2007). Molecular history of tuberculosis from ancient mummies and skeletons. Int. J. Osteoarchaeol. 17, 380-391. doi: 10.1002/oa.909
Zink, A. R., Reischl, U., Wolf, H., and Nerlich, A. G. (2002). Molecular analysis of ancient microbial infections. FEMS Microbiol. Lett. 213, 141-147. doi: 10.1111/ j.1574-6968.2002.tb11298.x

Conflict of Interest: The authors declare that the research was conducted in the absence of any commercial or financial relationships that could be construed as a potential conflict of interest.

Copyright (C) 2020 Arriola, Cooper and Weyrich. This is an open-access article distributed under the terms of the Creative Commons Attribution License (CC BY). The use, distribution or reproduction in other forums is permitted, provided the original author(s) and the copyright owner(s) are credited and that the original publication in this journal is cited, in accordance with accepted academic practice. No use, distribution or reproduction is permitted which does not comply with these terms. 